\title{
Wave energy potential along the northern coasts of the Gulf of Oman,
}

\section{Iran}

\author{
A. Saket*, A. Etemad-Shahidi** \\ School of Civil Engineering, Iran University of Science and Technology, Tehran, Iran, \\ P.O. Box 16765-163, Tel.: +9821 77240399, Fax: +9821 77240398. \\ *E-mail: arvin_s84@yahoo.com \\ **Corresponding Author, E-mail: etemad@iust.ac.ir
}

\begin{abstract}
This study aims to investigate wave power along the northern coasts of the Gulf of Oman. To simulate wave parameters the third generation spectral SWAN model was utilized, and the results were validated with buoy and ADCP data. First, annual energy was calculated in the study region with the hindcast dataset covering 23 years (1985-2007). The areas with the highest wave resource were determined and the area proximity to the port of Chabahar is suggested as the best site for the installation of a wave farm. Second, the average monthly wave energy in this area was investigated. The most energetic waves are provided by the southeast Indian Ocean monsoon from June to August. Finally, the wave energy resource was characterized in terms of sea state parameters. It was found that the bulk of annual wave energy occurs for significant wave heights between 1 and $3 \mathrm{~m}$ and energy periods between 4 and $8 \mathrm{~s}$ in the direction of SSE.
\end{abstract}

Keywords: Renewable energy, Wave energy, Wave climate, Gulf of Oman, SWAN 


\section{Introduction}

Growing energy consumption in the world and traditional methods of energy production have led to serious environmental problems. Nowadays, a long-term goal of a 50\% reduction in global greenhouse emissions before 2050 has been set by the Kyoto protocol [1]. Renewable energy sources have a key role in the reduction of air pollution, especially $\mathrm{CO}_{2}$ emission. Several energy sources which can be a good alternative for fossil energy are solar, wind and ocean energy (i.e. wave, tide and current). These sources of energy currently provide only a small amount of energy in world-wide [2], although they are expected to play a greater role in future energy provision.

Among the novel renewable energy sources, wave energy is one of the most promising [3]. Wave energy is seen as an enormous source of renewable energy with limited negative environmental impacts [4,5]. This kind of energy is more persistent than other sources of energy. The wave power flow just below the sea surface is about five times larger than that of wind power flow at the level $19.5 \mathrm{~m}$ above the sea surface [6]. Wave energy is unevenly distributed over the globe and depends on the geographical location and time [7,8]. The potential of worldwide wave energy in deep water has been estimated between 1 and $10 \mathrm{TW}$, which is comparable with the world's power consumption [9]. Although waves advancing from offshore towards nearshore lose their energy due to bottom friction and wave breaking [10], both nearshore and offshore locations can be envisaged for wave farms. Usually, the economics dictate the site selection for wave farms, taking into account the differences in the resource and the cost of the wave energy converters (WECs) and submarine connection to the land network [10,11].

Technologies for transforming wave energy into electricity are still in the development stage [12]. Each technology has different efficiencies under different sea states. Several researchers 
have studied different ways to improve and optimize WECs (e.g. [13-15]). It is known that the characteristics of the wave energy resource, in terms of wave parameters, are important for choosing the most appropriate WEC for an area and tuning an existing wave energy converter design [11]. WECs have maximum efficiency in the ranges of wave heights and periods, which provide the majority of the energy [16].

This study investigates the quantity of wave energy in deep water along the coasts of the Gulf of Oman, Iran. To simulate wave parameters the third generation spectral SWAN model was utilized, and the results were calibrated and verified with buoy measurements. Wave parameters were hindcasted for 23 years (1985-2007) and the annual and quarterly wave energy in high-energy spots were estimated. In addition, the wave energy resource was characterized in terms of sea state parameters (significant wave heights, energy periods and mean directions) for choosing the most appropriate WECs in the selected sites which have the highest potential for wave farms.

The present study is organized as follows. Section 2 presents the study area and the field data. Methods are discussed in section 3. In this section the mathematical background and wave model used to hindcast data are introduced, and the validation of the model with buoy measurements is discussed. Section 4 presents the results and discussions: the area with the highest potential for a wave farm, the monthly variations of wave energy and characterization of the wave energy potential to select the WECs in the specified area. Finally, summary and conclusions are drawn in section 5 .

\section{Study area and field data}

2.1. Study area 
The Gulf of Oman is the northwestern part of the Arabian Sea, bounded by Iran on the north, Oman on the south, and the United Arab Emirates on the west (Fig. 1). This gulf is connected to the Indian Ocean in the South-East by the Arabian Sea and is one of the most important waterways in the world. It is about $545 \mathrm{~km}$ long and its width varies from $56 \mathrm{~km}$ (at the Strait of Hormuz) to $370 \mathrm{~km}$. The climate in this region is partly similar to that of the Indian Ocean. Gulf of Oman is mainly affected by seasonal winds, called monsoons. The average wind speed is the highest in July and comes from the Indian Ocean. The wind rose of the area near the coast of Iran for 23 years (1985 to 2007) is illustrated in Fig. 2.

The Gulf of Oman's northern coastline consists of the sea boundary of the two southern provinces of Iran, namely Hormozgan and Sistan va Baluchestan. The Chabahar zone in Sistan va Baluchestan province is the closest coast of Iran to the Indian Ocean, and the most energetic wave climate is found there (Fig. 1). The weather is hot and dry, therefore electrical energy has a great role in this area. In addition, Chabahar Bay is one of the marine sensitive areas of Iran. Several sensitive species of marine flora and fauna, such as mangrove forests, coral reefs and sea turtles, have been identified in this area [18,19]. Taking into account these reasons, the aim of this study is to estimate the wave energy along the coast of Chabahar zone, between the longitude of $59^{\circ} \mathrm{E}-61.6^{\circ} \mathrm{E}$ and the latitude of $25^{\circ} \mathrm{N}-25.45^{\circ} \mathrm{N}$.

\subsection{Field data}

The recorded wave data used in this study were collected by a Datawell Directional Waverider buoy and an ADCP. The buoy and ADCP were located near the port of Chabahar at $60.65^{\circ} \mathrm{E}$ and $25.267^{\circ} \mathrm{N}$, and $60.534^{\circ} \mathrm{E}$ and $25.234^{\circ} \mathrm{N}$, respectively. They were deployed by Islamic Republic of Iran Meteorological Organization (IRIMO) (Fig. 1). The water depth was 
about $17 \mathrm{~m}$ at the location of buoy and the data set was collected three-hourly from May, 1998 to September, 2000 with some gaps. The ADCP was installed at water depth of $30 \mathrm{~m}$ and the data set was recorded hourly from August, 2006 to June, 2007 with some gaps.

Since the results of any numerical wave hindcast study depend on the quality of the wind data, to gain reliable wave hindcasting, it is essential to select an appropriate input wind field [20-23]. Therefore, a measured wind field integrated with the meteorological stations near the shoreline and QuikSCAT satellite data was used as the wind input in the SWAN model. The wind data in these stations have been recorded 3-hourly from the 1985 to 2007, continuously. This wind field covered the Gulf of Oman with a resolution of $0.5^{\circ} \times 0.5^{\circ}$.

\section{Methods}

\subsection{Mathematical background}

Real sea waves are described as composed of many waves of different frequencies, amplitudes and directions. Based on the directional wave energy spectrum $S(f, \theta)$, it is possible to describe these wave parameters. The wave power level in terms of the wave spectrum can be defined as:

$$
J=\rho g \int_{0}^{2 \pi} \int_{0}^{\infty} C_{g}(f, h) S(f, \theta) d f d \theta
$$

where $\rho$ is the mass density of sea water $\left(1025 \mathrm{~kg} / \mathrm{m}^{3}\right), g$ is the gravitational acceleration and $C_{g}$ is the group velocity, described as:

$$
C_{g}(f, h)=\frac{g}{4 \pi f}\left(1+\frac{2 k h}{\sinh (2 k h)}\right) \tanh (k h)
$$

where $f$ is the wave frequency, $h$ is the water depth, $k=2 \pi / L$ is the wave number and $L$ is the wave length. In deep water $C_{g}=g / 4 \pi f$, therefore 


$$
J=\frac{\rho g^{2}}{4 \pi} \int_{0}^{2 \pi} \int_{0}^{\infty} f^{-1} S(f, \theta) d f d \theta
$$

The spectral moments of order $n$ are defined as:

$$
m_{n}=\int_{0}^{2 \pi} \int_{0}^{\infty} f^{n} S(f, \theta) d f d \theta
$$

The energy period $\left(T_{e}\right)$ of the sea state and the significant wave height $\left(H_{s}\right)$ in terms of the spectral moment respectively are given by:

$$
\begin{aligned}
& T_{e}=T_{-1,0}=\frac{m_{-1}}{m_{0}} \\
& H_{s}=H_{m 0}=4\left(m_{0}\right)^{1 / 2}
\end{aligned}
$$

Therefore, the wave energy flux per unit width of the progressing wave front in terms of energy period and significant wave height in deep water is approximated:

$$
J=\frac{\rho g^{2}}{64 \pi} T_{e} H_{s}^{2} \cong 0.5 T_{e} H_{s}^{2} \quad k W / m
$$

If a certain wave energy converter (WEC) captures the energy of a width $b$ of wave front, the corresponding power is:

$$
J_{W E C}=J b
$$

\subsection{Numerical model}

The spectral wave model SWAN (Simulating Waves Nearshore) [24,25] was used for wave simulation. SWAN is a third-generation spectral wind wave model, developed for obtaining reliable estimates of wave parameters in coastal areas. The model solves the transport equation with no particular shape which is assumed for the wave spectrum [26-28]. Action density spectrum is considered in SWAN model rather than energy density spectrum because, unlike energy density, action density is conserved in the presence of currents. Action density is defined as: 


$$
N(\sigma, \theta)=E(\sigma, \theta) / \sigma
$$

where $E(\sigma, \theta)$ is the energy density with $\sigma$ the relative frequency (i.e. the radian frequency in a frame of reference moving with current velocity) and $\theta$ the propagation direction (i.e. the direction normal to the wave crest of each spectral component).

The SWAN model solves the spectral action balance equation for the Cartesian coordinates [25]:

$$
\frac{\partial}{\partial t} N+\frac{\partial}{\partial x} c_{x} N+\frac{\partial}{\partial y} c_{y} N+\frac{\partial}{\partial \sigma} c_{\sigma} N+\frac{\partial}{\partial \theta} c_{\theta} N=\frac{S}{\sigma}
$$

The first term on the left-hand side shows the local rate of change of action density in time, the next two terms represent the propagation of action in geographical space where $c_{x}$ and $c_{y}$ are the propagation velocity in the $x$ and $y$-spaces, respectively. The fourth term represents the shifting of the relative frequency due to variations in depths and currents in which, $c_{\sigma}$ is the propagation velocity in the $\sigma$-space. The last term on the left-hand side demonstrates depthinduced and current-induced refraction and propagation in directional space in which, $c_{\theta}$ is the propagation velocity in the $\theta$-space [24]. The term $S=S(\sigma, \theta)$ represents sources or sinks of wave energy. This term shows the effects of generation, dissipation (by whitecapping, bottom friction and depth-induced wave breaking) and nonlinear wave-wave interactions. Further details can be found in $[24,25,29]$. In this study, SWAN cycle III version 40.72AB [30] was employed.

\subsection{Validation of the wave model}

For simulating the wave parameters, the SWAN model was executed in the two-dimensional nonstationary mode. The model was implemented on nautical coordinates covering the Gulf of Oman. The geographical domain was divided into $92 \times 82$ uniform cells with $0.0333^{\circ}$ resolutions in $x$ and $y$ directions, respectively. The bathymetry data was obtained from the Iranian National 
Center for Oceanography (INCO). The spectral space was resolved in 18 directions $\left(20^{\circ}\right.$ angular bandwidth) and 25 logarithmically spaced frequencies, between $0.04 \mathrm{~Hz}$ and $1 \mathrm{~Hz}$. The Cumulative Steepness Method (CSM) [31] was used for approximating whitecapping. Quadruplet nonlinear interactions, depth-induced wave breaking and bottom friction were activated in the model. The model execution time step was selected as 10 minutes.

The calibration of the model is a process that the model parameters are tuned to obtain best results against the measurements. For calibration of the model, recorded wave data from $16 / 02 / 2000$ to $04 / 03 / 2000$ with a wide range of wave conditions was selected. The sensitivity analysis showed that the depth-induced wave breaking and bottom friction coefficients had negligible effect on the wave characteristics. Therefore, the default values were selected for these tunable parameters in the mentioned sink terms. The whitecapping dissipation coefficient was the tunable parameter used for calibration of the model [32]. The default tunable coefficient value of whitecapping $(\mathrm{cst}=4.0)$ led to the underestimation of the results. To obtain the best simulation for both wave height and period, the value of this parameter was decreased to 0.055 .

A qualitative view of the calibration result, in terms of significant wave height and wave energy, is illustrated in Fig.3. As seen, there is a very good agreement between the model results and measurements, both in terms of significant wave height and wave energy. For the quantitative comparison of the results, the following statistics were used:

$$
\begin{aligned}
& M A P E=\frac{1}{n} \sum \frac{\left|x_{i}-y_{i}\right|}{x_{i}} \times 100 \\
& R=\frac{\sum\left(x_{i}-\bar{x}\right)\left(y_{i}-\bar{y}\right)}{\sqrt{\sum\left(x_{i}-\bar{x}\right)^{2} \sum\left(y_{i}-\bar{y}\right)^{2}}}
\end{aligned}
$$

where $M A P E$ is the mean absolute percentage error and $R$ is the correlation coefficient. $x_{i}$ represents the measured data and $y_{i}$ represents the modeled data. $\bar{x}$ and $\bar{y}$ are the mean value of 
measured and modeled data, respectively and $n$ is the total number of data. The summary of statistical analysis for the calibration period is given in Table 1.

After calibration, the model was verified using the buoy recorded data from 20/01/1999 to 05/02/1999 and ADCP recorded data from 11/05/2007 to 10/06/2007. Time series of the modeled significant wave heights and wave energy against the buoy and ADCP measurements during the verification period are shown in Fig. 4 and Fig. 5, respectively. As seen, similar to the calibration period, the model performs well in simulating $H_{s}$ and $J$. For quantitative comparison of the results, the error measures are shown in Table 2. This table shows that the results of the verification are in agreement with those of the calibration period.

\section{Results and discussions}

\subsection{Hot spots}

After validating the wave model, it was used to determine the locations with the largest wave energy (hot spots) in the Gulf of Oman along the coasts of Iran (Fig. 1). Significant wave heights and energy periods were simulated for 23 years in the studied sites and the wave energy was calculated using equation (7). Four areas were found with the largest annual wave energy in this region (Fig. 6). Their location, water depth, distance to the coastline and annual wave energy are given in Table 3. These points are located in deep water and approximately near the coastline. It is apparent from the last column of Table 3 that there is no significant difference between annual energies of A to D and one cannot distinguish between these areas in terms of annual wave energy.

In selecting the area to extract wave energy, the wave resource is not the only issue to be considered. The construction and operational costs are important as well [16]. One of the most 
important factors for selecting an area for the installation of a wave farm is the proximity to the cities. There are no cities near the A, B and C stations and the population density is low near these areas. Therefore, there is no economic justification to extract wave energy in these sites. The port of Chabahar in the south-east of Sistan va Baluchestan Province is located near the site D (Fig. 6). The port of Chabahar is a free trade-industrial zone. Because of its establishment near the Indian Ocean, it is the center of business, trade and navigation in this province. Thus, site D is suggested the best area for the installation of a wave farm.

\subsection{Average monthly wave energy}

After selecting the area with the highest potential for a wave farm (site D), the monthly variations of wave energy in this area were studied. The annual distribution of wave energy on a monthly basis is plotted in Fig. 7. This figure shows that the monthly averaged wave power varies between $0.97 \mathrm{~kW} / \mathrm{m}$ and $5.16 \mathrm{~kW} / \mathrm{m}$. The highest average energy occurs during July and August, and the lowest are associated with autumn in October and November.

As seen, the intensity of wave energy fluctuates seasonally. It is apparent that the wave climate can be divided into three periods. The first is from January to May, the second (with the highest energy) is from June to August and third is from September to December, which represents the calm season. The wave roses of these three periods for site D are illustrated in Fig.8. As seen, the prevailing wave direction of larger wave heights veers from SW in the first 
period to SSE-SE in the second period. The highest waves are coming from the southeast, due to the southwest Indian Ocean monsoon, and the bulk of energy can be extracted from these waves.

\subsection{Characterization of the wave energy potential}

The wave energy converters have their maximum efficiency in the ranges of wave heights and periods that provide the bulk of the energy. Therefore, the characterization of the wave energy potential in terms of sea states is important in selecting the WECs. For this purpose, the threehourly values of significant wave height and energy period within the period 1985-2007 were investigated for this area. To indicate the random variability in the sea states, the joint significant wave height and energy period distribution in the period 1985-2007 was tabulated considering six significant wave height intervals and seven energy period intervals. The results of the $\left(H_{s}, T_{e}\right)$ analysis at site $\mathrm{D}$, with wave energy data expressed in $\mathrm{MWh} / \mathrm{m}$ and the percentage of the total energy corresponding to each interval are shown in Table 4.

As seen, the waves with heights less than $1 \mathrm{~m}$ and energy period between 2 and $6 \mathrm{~s}$ have the largest probabilities of occurrence, but the bulk of energy is associated with waves of larger heights and periods with lower probabilities of occurrence. Therefore, the selection of WECs should aim for maximum efficiency in the ranges between 1 and $3 \mathrm{~m}$ in terms of significant wave height and between 4 and $8 \mathrm{~s}$ in terms of energy period. 
For investigation of annual wave energy direction, the combination of significant wave height intervals and mean wave directions of site $\mathrm{D}$ is depicted in Table 5. The sea states in the period 1985-2007 were ascribed to these intervals and the corresponding time percentages computed. As seen, the main directions with the largest probabilities of occurrence for whole year are SSE, S and SSW. This table shows that, the prevailing wave direction for selecting the appropriate WEC corresponds to SSE direction, i.e. the waves are coming from the Indian Ocean to this area.

\section{Summary and conclusions}

In this study, wave power along the northern coasts of the Gulf of Oman was investigated. This region is the southeastern coast of Iran and has been identified as a sensitive marine area. To determine the wave climate, a hindcast dataset covering 23 years (1985-2007) was used. This dataset was obtained from numerical modeling. The wave model SWAN was implemented to simulate wave parameters. For validation, the numerical data series of significant wave height and wave energy were compared with buoy and ADCP measurements. Very good agreements were found between the hindcast data set and the in-situ measurements.

Having successfully validated the wave model, annual wave energy was calculated from significant wave height and energy period in the study area. The energy resource in the four areas with the largest energy was found very similar and their wave energy was estimated to be around $2.8 \mathrm{~kW} / \mathrm{m}$ in an average year. Among these sites, the easternmost site near to the Chabahar port, was identified as the most appropriate area for wave energy extraction. Moreover, the monthly variations of wave energy in this area were analyzed. The wave climate in an average year was divided into three periods. The most energetic waves occur in the second 
period which is from June to August. These waves come from the SSE direction, during the Indian Ocean monsoon.

Finally, the characteristics of the wave energy resource in terms of significant wave heights, energy periods, and wave directions were discussed. The bulk of energy was found in sea states with a significant wave height between 1 and $3 \mathrm{~m}$ and an energy period between 4 and 8 s, so the WECs have maximum efficiency in the ranges of $H_{s}$ and $T_{e}$. In addition, the main wave direction was found the SSE, for installation of WECs with the maximum capability.

Although the amount of wave energy estimated along the coast of Chabahar is low, the available wave power is still a remarkable energy source in this area. With increasing WECs efficiency in the future and advancing technological capabilities for extracting wave energy, the extractable energy might eventually become more than expected today.

\section{Acknowledgments}

The authors would like to thank Islamic Republic of Iran Meteorological Organization (IRIMO) for providing the buoy and wind data and JPLPO.DAAC for providing the QuikSCAT data. The authors would also thank the SWAN group at the Delft University of Technology (Department of Fluid Mechanics) for providing the freely available model. We also thank MH Moeini and B Kamranzad for their helpful suggestions; and D Keech for editing the manuscript. This study was supported by the Deputy of Research, Iran University of Science and Technology (IUST). 


\section{References}

[1] M. Özger, Prediction of ocean wave energy from meteorological variables by fuzzy logic modeling, Expert Systems with Applications, 38 (2011) 6269-6274.

[2] S.C. Pryor, R.J. Barthelmie, Climate change impacts on wind energy: A review, Renewable and Sustainable Energy Reviews, 14 (2010) 430-437.

[3] G. Iglesias, M. López, R. Carballo, A. Castro, J.A. Fraguela, P. Frigaard, Wave energy potential in Galicia (NW Spain), Renewable Energy, 34 (2009) 2323-2333.

[4] M. Leijon, H. Bernhoff, M. Berg, O. Ågren, Economical considerations of renewable electric energy production--especially development of wave energy, Renewable Energy, 28 (2003) 1201-1209.

[5] A. Clément, P. McCullen, A. Falcão, A. Fiorentino, F. Gardner, K. Hammarlund, G. Lemonis, T. Lewis, K. Nielsen, S. Petroncini, M.T. Pontes, P. Schild, B.-O. Sjöström, H.C. Sørensen, T. Thorpe, Wave energy in Europe: current status and perspectives, Renewable and Sustainable Energy Reviews, 6 (2002) 405-431.

[6] J. Falnes, A review of wave-energy extraction, Marine Structures, 20 (2007) 185-201.

[7] A.Q. Malik, Assessment of the potential of renewables for Brunei Darussalam, Renewable and Sustainable Energy Reviews, 15 (2011) 427-437.

[8] A. Angelis-Dimakis, M. Biberacher, J. Dominguez, G. Fiorese, S. Gadocha, E. Gnansounou, G. Guariso, A. Kartalidis, L. Panichelli, I. Pinedo, M. Robba, Methods and tools to evaluate the availability of renewable energy sources, Renewable and Sustainable Energy Reviews, 15 (2011) 1182-1200. 
[9] N.N. Panicker, Power resource potential of ocean surface wave, in: The wave and salinity gradient workshop, Newark, Delaware, USA, 1976, pp. J1-J48.

[10] M. Folley, T.J.T. Whittaker, Analysis of the nearshore wave energy resource, Renewable Energy, 34 (2009) 1709-1715.

[11] G. Iglesias, R. Carballo, Wave energy and nearshore hot spots: The case of the SE Bay of Biscay, Renewable Energy, 35 (2010) 2490-2500.

[12] A.F.d.O. Falcão, Wave energy utilization: A review of the technologies, Renewable and Sustainable Energy Reviews, 14 (2010) 899-918.

[13] I.A. Ivanova, H. Bernhoff, O. Ågren, M. Leijon, Simulated generator for wave energy extraction in deep water, Ocean Engineering, 32 (2005) 1664-1678.

[14] E.B. Agamloh, A.K. Wallace, A. von Jouanne, A novel direct-drive ocean wave energy extraction concept with contact-less force transmission system, Renewable Energy, 33 (2008) 520-529.

[15] D. Elwood, S.C. Yim, J. Prudell, C. Stillinger, A. von Jouanne, T. Brekken, A. Brown, R. Paasch, Design, construction, and ocean testing of a taut-moored dual-body wave energy converter with a linear generator power take-off, Renewable Energy, 35 (2010) 348-354.

[16] G. Iglesias, R. Carballo, Wave power for La Isla Bonita, Energy, 35 (2010) 5013-5021.

[17] M.H. Moeini, A. Etemad-Shahidi, V. Chegini, Wave modeling and extreme value analysis off the northern coast of the Persian Gulf, Applied Ocean Research, 32 (2010) 209-218.

[18] A. Danehkar, Marine sensitive areas of Iran, MOHIT-E-ZIST, 24 (1998) 28-38 (in Persian). 
[19] M.A. Zahed, F. Rouhani, S. Mohajeri, F. Bateni, L. Mohajeri, An overview of Iranian mangrove ecosystems, northern part of the Persian Gulf and Oman Sea, Acta Ecologica Sinica, 30 (2010) 240-244.

[20] J.C. Teixeira, M.P. Abreu, C. Guedes Soares, Uncertainty of OceanWave Hindcasts due to Wind Modelling, J. Offshore Mech. Arc. Eng., 117 (1995) 294-297.

[21] L.H. Holthuijsen, N. Booji, L. Bertotti, The propagation of wind errors through ocean wave hindcasts, J. Offshore Mech. Arc. Eng., 118 (1996) 184-189.

[22] S. Ponce de León, F.J. Ocampo-Torres, Sensitivity of a wave model to wind variability, Journal of Geophysical Research, 103 (1998) 3179-3201.

[23] S. Ponce de León, C. Guedes Soares, Sensitivity of wave model predictions to wind fields in the Western Mediterranean sea, coastal Engineering, 55 (2008) 920-929.

[24] N. Booij, R.C. Ris, L.H. Holthuijsen, A third-generation wave model for coastal regions 1. Model description and validation, Journal of Geophysical Research C: Oceans, 104 (1999) 7649-7666.

[25] R.C. Ris, L.H. Holthuijsen, N. Booij, A third-generation wave model for coastal regions 2. Verification, Journal of Geophysical Research C: Oceans, 104 (1999) 7667-7681.

[26] WAMDI group. The WAM model - a third generation ocean wave prediction model, J. PHYS. OCEANOGR., 18 (1988) 1775-1810.

[27] G.J. Komen, S. Hasselmann, K. Hasselmann, On the existence of a fully developed windsea spectrum, J. PHYS. OCEANOGR., 14 (1984) 1271-1285. 
[28] R. Bolaños-Sanchez, A. Sanchez-Arcilla, J. Cateura, Evaluation of two atmospheric models for wind-wave modelling in the NW Mediterranean, Journal of Marine Systems, 65 (2007) 336-353.

[29] L.H. Holthuijsen, N. Booij, T.H.C. Herbers, A prediction model for stationary, shortcrested waves in shallow water with ambient currents, coastal Engineering, 13 (1989) 2354.

[30] The SWAN team. SWAN User Manual (Cycle III version 40.72AB), Delft University of Technology, Delft, (2009).

[31] D.P. Hurdle, G.P. Van Vledder, Improved spectral wave modelling of white-capping dissipation in swell sea systems, in, 2004, pp. 539-544.

[32] M.H. Moeini, A. Etemad-Shahidi, Application of two numerical models for wave hindcasting in Lake Erie, Applied Ocean Research, 29 (2007) 137-145. 


\section{Figures Caption:}

Fig. 1. The Gulf of Oman and the locations of buoy and ADCP [17].

Fig. 2. Wind rose of the study area, 1985 to 2007.

Fig. 3. Comparison between the modeled and buoy recorded parameters, calibration period: (a) significant wave height; (b) wave energy.

Fig. 4. Comparison between the modeled and buoy recorded parameters, verification period: (a) significant wave height; (b) wave energy.

Fig. 5. Comparison between the modeled and ADCP recorded parameters, verification period:

(a) significant wave height; (b) wave energy.

Fig. 6. The location of sites A to D along Sistan va Baluchestan coasts.

Fig. 7. Monthly average wave energy $(\mathrm{kW} / \mathrm{m})$, Site D.

Fig. 8. Wave height roses from (a) January to May, (b) June to August and (c) September to December, site D. 


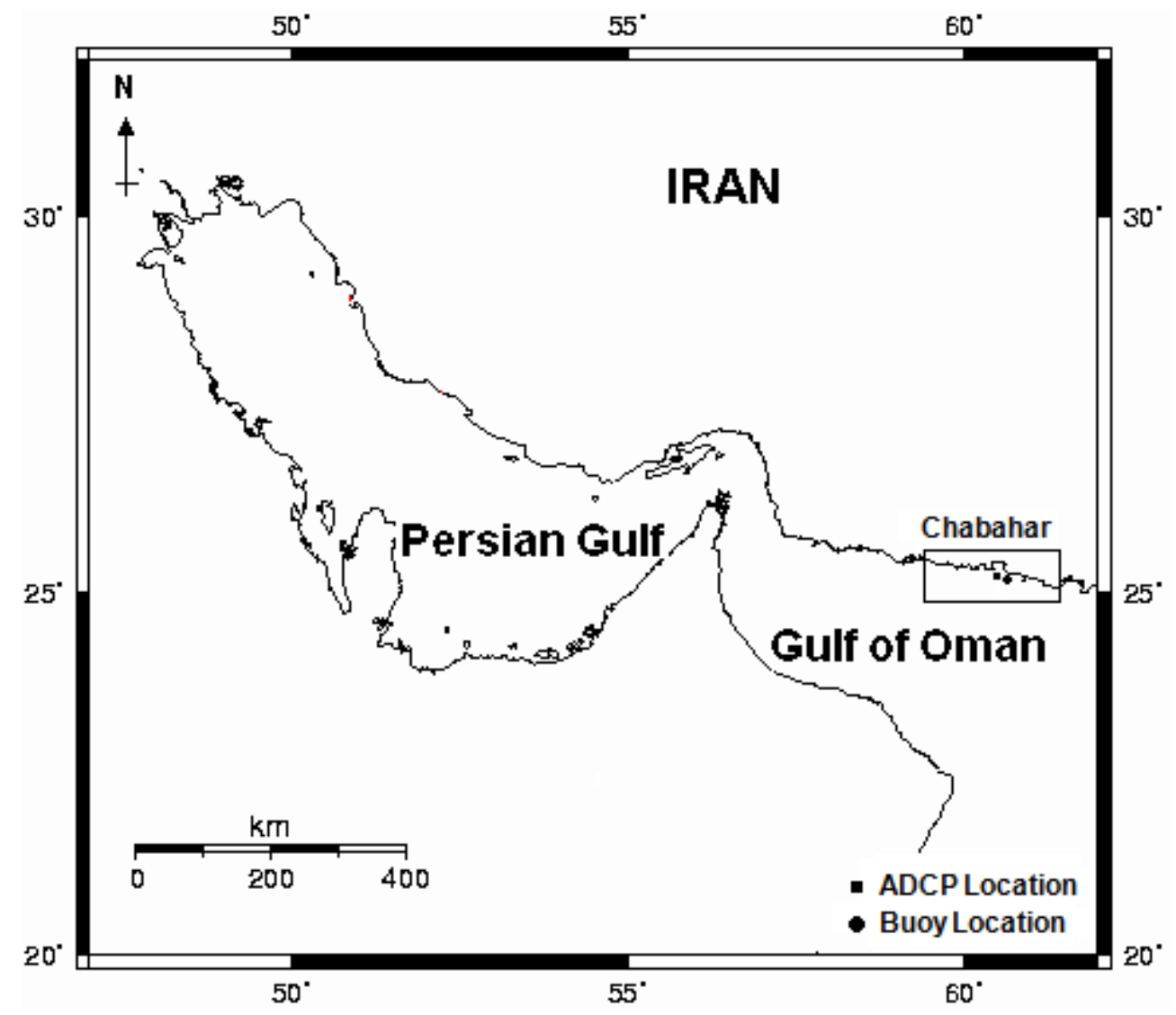

Fig. 1. The Gulf of Oman and the locations of buoy and ADCP [17]. 


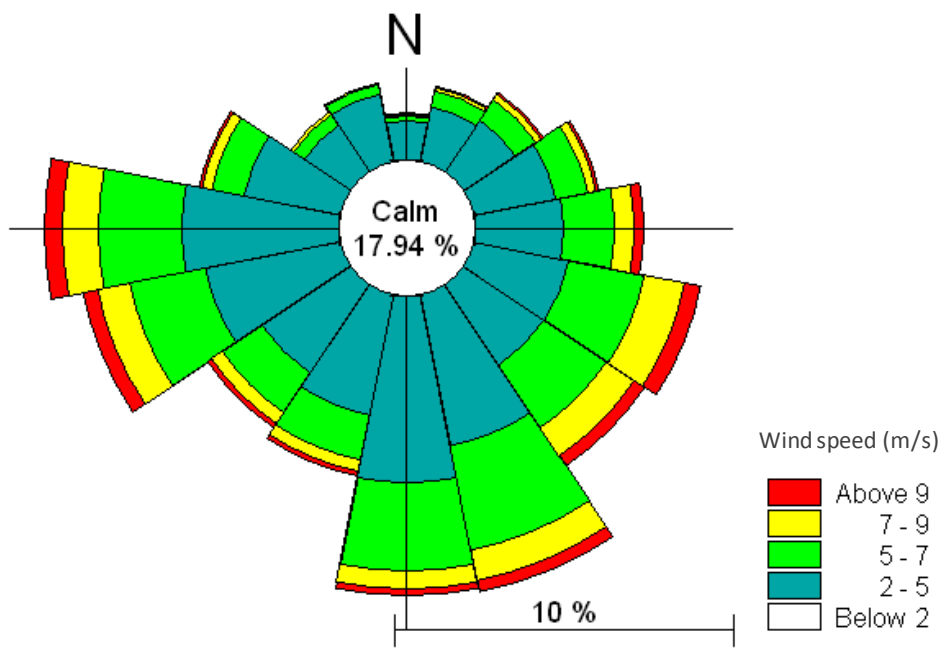

Fig. 2. Wind rose of the study area, 1985 to 2007. 

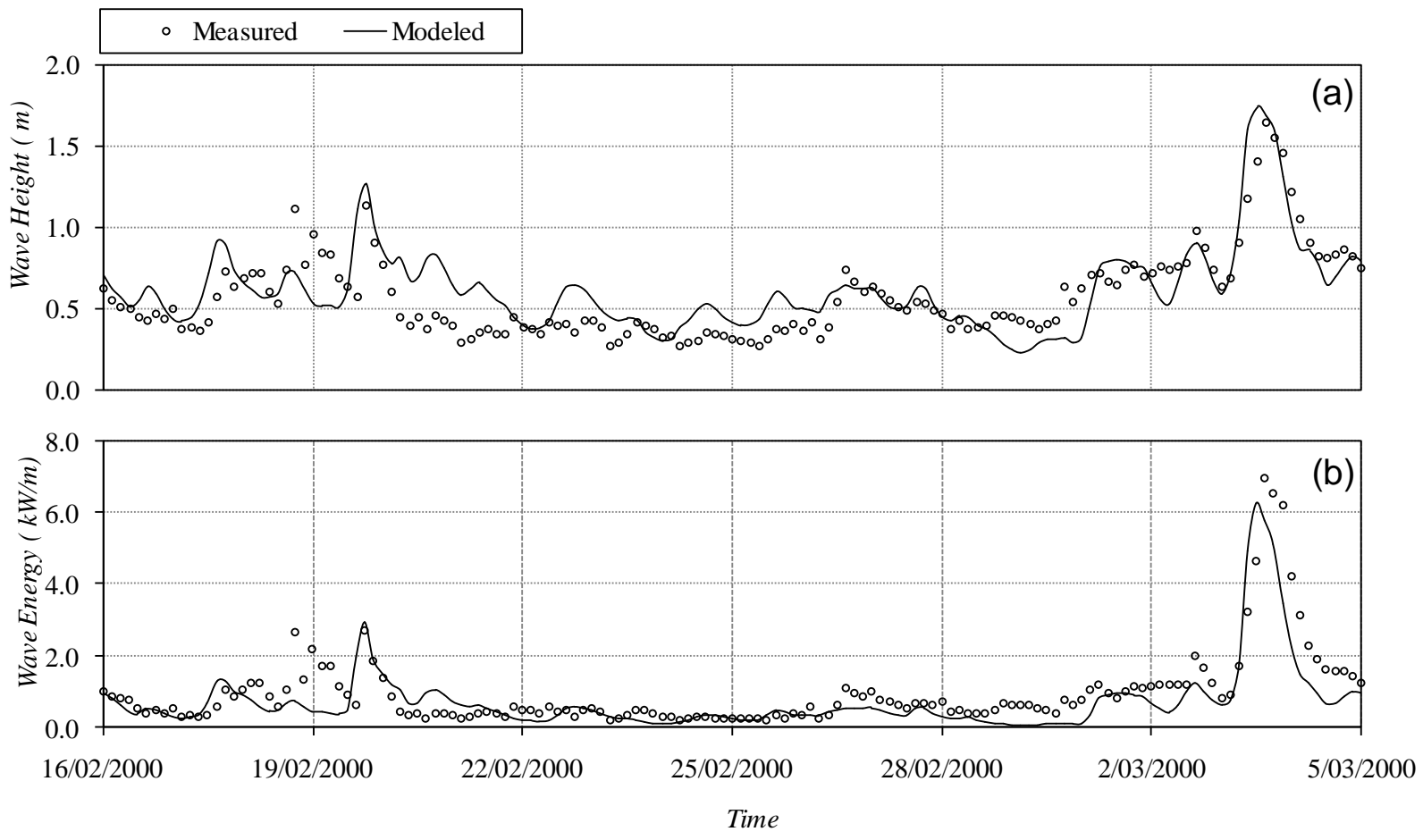

Fig. 3. Comparison between the modeled and buoy recorded parameters, calibration period: (a) significant wave height; (b) wave energy. 


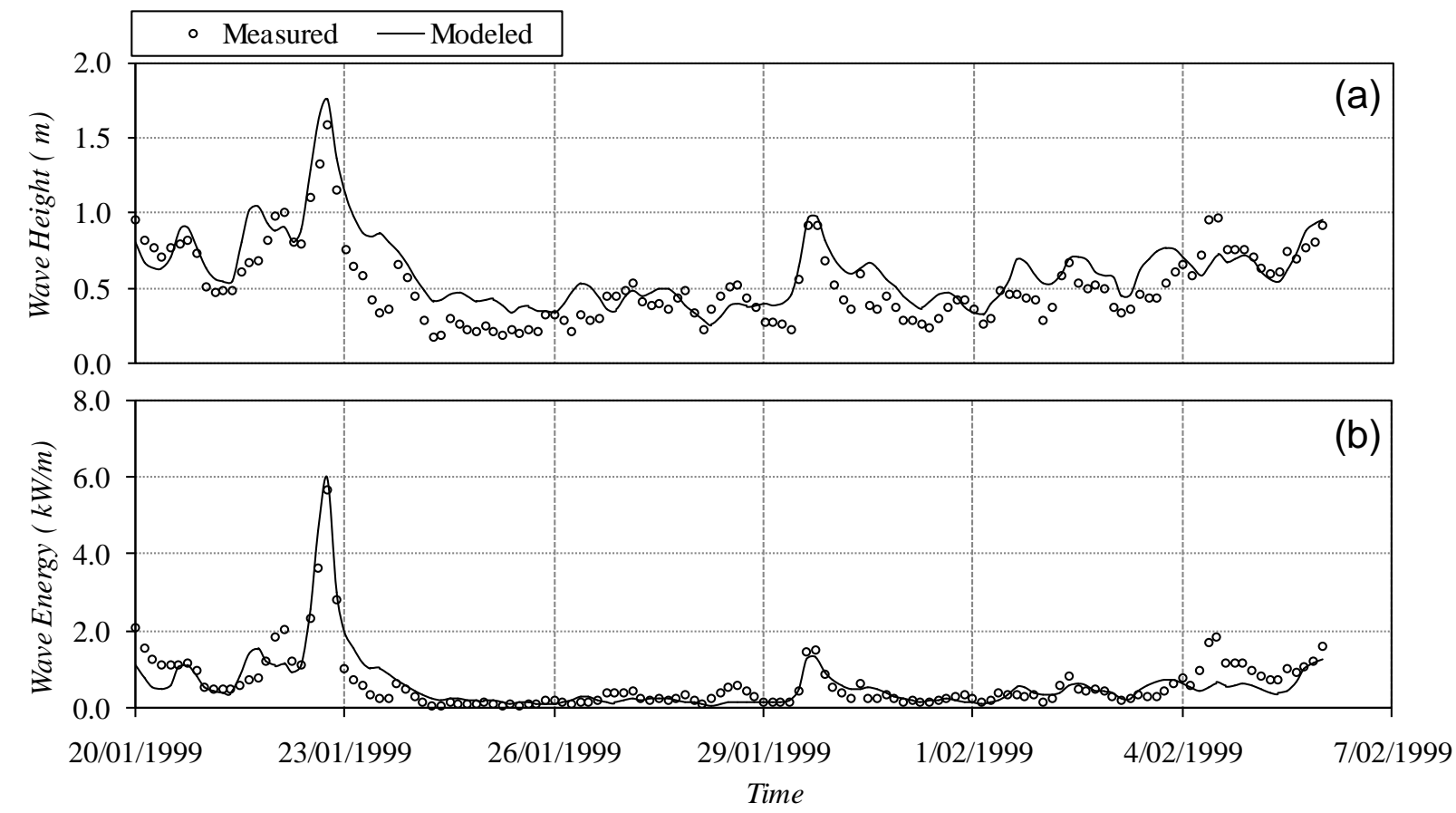

Fig. 4. Comparison between the modeled and buoy recorded parameters, verification period: (a) significant wave height; (b) wave energy. 

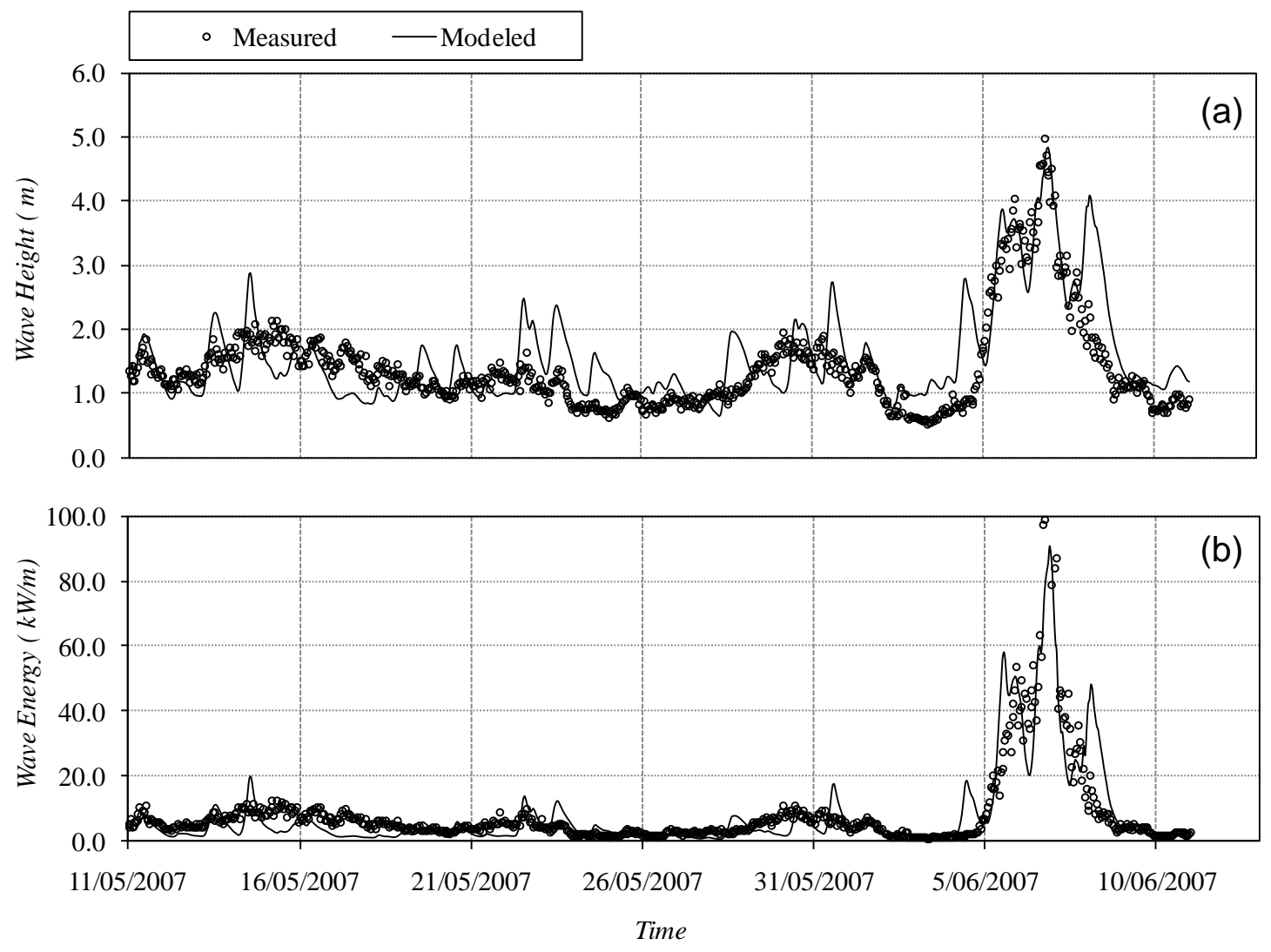

Fig. 5. Comparison between the modeled and ADCP recorded parameters, verification period: (a) significant wave height; (b) wave energy. 


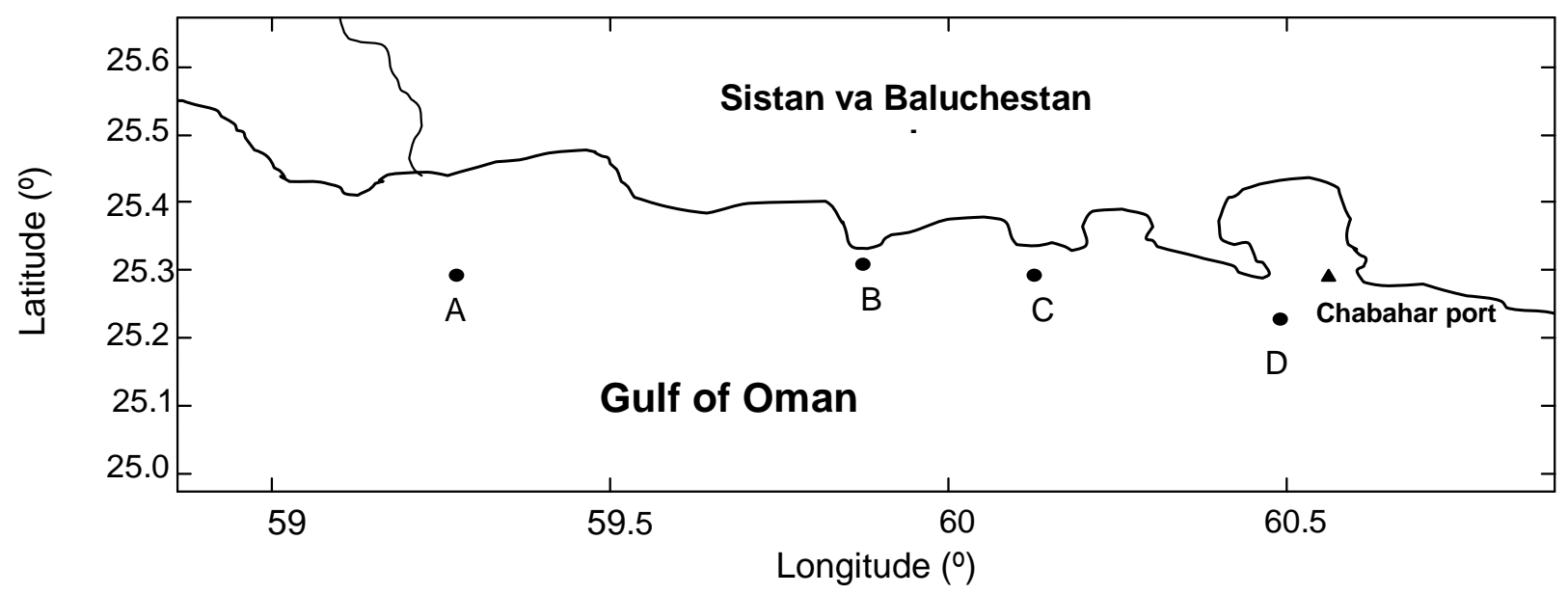

Fig.6. The location of sites A to D along Sistan va Baluchestan coasts. 


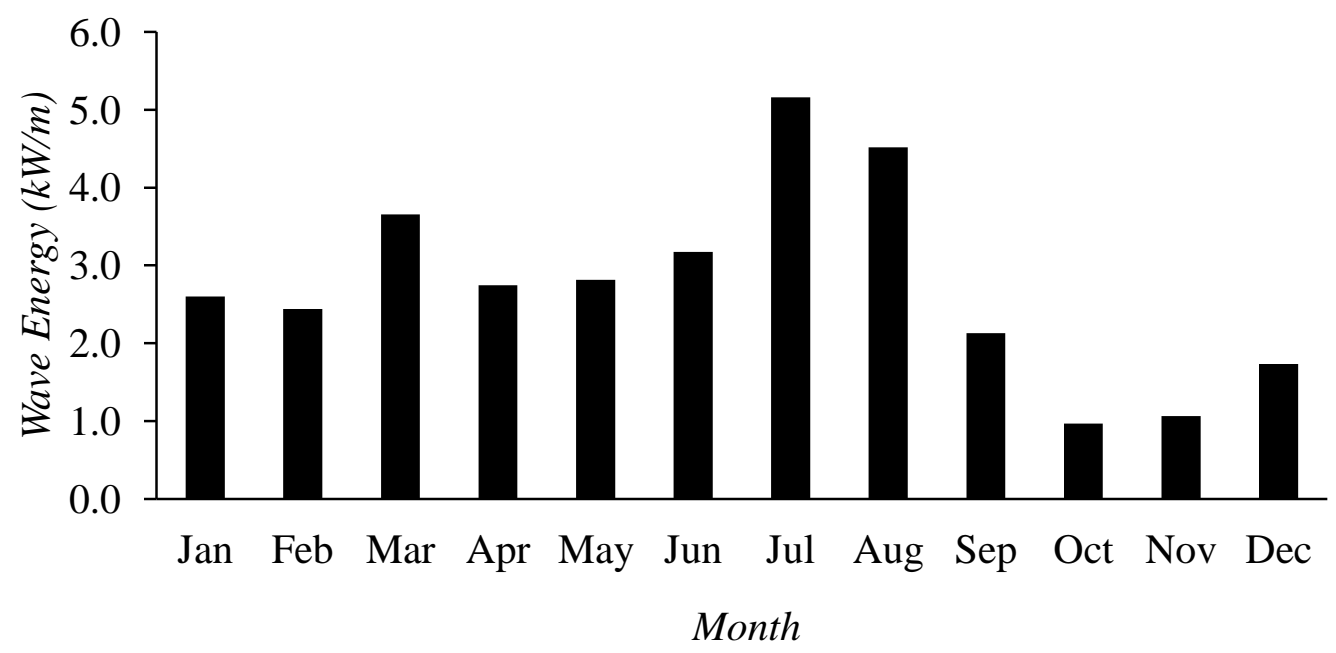

Fig. 7. Monthly average wave energy $(\mathrm{kW} / \mathrm{m})$, site $\mathrm{D}$. 
(a)

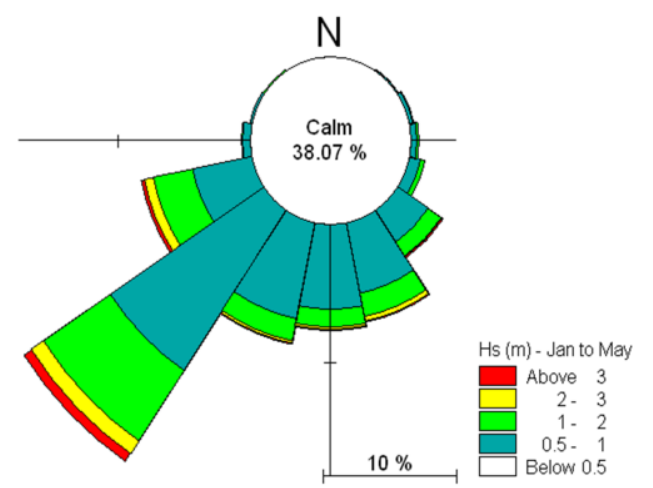

(c)

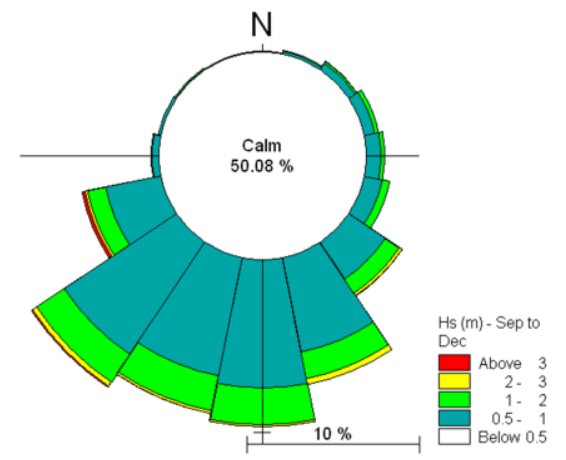

(b)

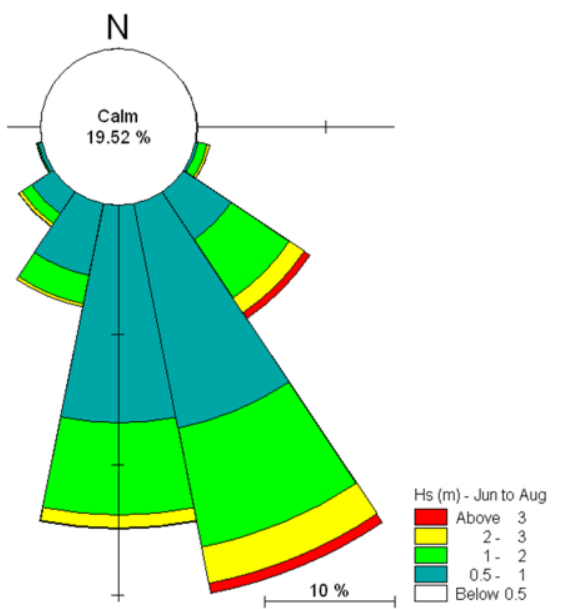

Fig. 8. Wave height roses from (a) January to May, (b) June to August and (c) September to December, site D. 


\section{Table's Caption:}

Table 1 . The summary of statistical analysis of the calibration period

Table 2. The summary of statistical analysis of the verification period

Table 3. The location, water depth, distance to the coastline and annual wave energy of sites A to D.

Table 4. Annual wave energy corresponding to sea states in different ranges of $H_{s}$ and $T_{e}$, and the percentage of the total annual energy, site D.

Table 5. Percentage of total time in an average year of sea states in different ranges of mean wave direction and $H_{s}$, site $\mathrm{D}$. 
Table 1 . The summary of statistical analysis of the calibration period

\begin{tabular}{ccc}
\hline \multirow{2}{*}{$H_{S}(m)$} & $M A P E(\%)$ & 12.8 \\
& $R$ & 0.80 \\
\hline \multirow{2}{*}{$J(k W / m)$} & $M A P E(\%)$ & 8.6 \\
& $R$ & 0.85 \\
\hline
\end{tabular}


Table 2 . The summary of statistical analysis of the verification period

\begin{tabular}{cccc}
\hline & & Buoy & ADCP \\
\hline \multirow{2}{*}{$H_{s}(m)$} & $M A P E(\%)$ & 27.2 & 19.0 \\
& $R$ & 0.84 & 0.70 \\
\hline \multirow{2}{*}{$J(k W / m)$} & $M A P E(\%)$ & 16.7 & 9.2 \\
& $R$ & 0.87 & 0.78 \\
\hline
\end{tabular}


Table 3. The location, water depth, distance to the coastline and annual wave energy of sites A to D.

\begin{tabular}{cccccc}
\hline Station ID & $\begin{array}{c}\text { Latitude } \\
\left({ }^{\circ}\right) \mathrm{N}\end{array}$ & $\begin{array}{c}\text { Longitude } \\
\left({ }^{\circ}\right) \mathrm{E}\end{array}$ & $\begin{array}{c}\text { Depth } \\
(\mathrm{m})\end{array}$ & $\begin{array}{c}\text { Distance to coastline } \\
(\mathrm{km})\end{array}$ & $\begin{array}{c}J_{\text {mean }} \\
(\mathrm{kW} / \mathrm{m})\end{array}$ \\
\hline A & 25.28 & 59.27 & 38.2 & 17 & 2.7 \\
B & 25.32 & 59.87 & 41 & 4.5 & 2.82 \\
C & 25.28 & 60.14 & 40.9 & 7 & 2.78 \\
D & 25.22 & 60.47 & 38 & 7.5 & 2.72 \\
\hline
\end{tabular}


Table 4. Annual wave energy corresponding to sea states in different ranges of $H_{s}$ and $T_{e}$, and the percentage of the total annual energy, site D.

\begin{tabular}{|c|c|c|c|c|c|c|c|c|c|}
\hline \multirow{2}{*}{$H_{s}(\mathrm{~m})$} & & \multicolumn{8}{|c|}{$T_{e}(\mathrm{~s})$} \\
\hline & & $<2$ & $2-4$ & $4-6$ & $6-8$ & $8-10$ & $10-12$ & $>12$ & Total \\
\hline \multirow{2}{*}{$>4$} & $E(\mathrm{kWh} / \mathrm{m})$ & 0.00 & 0.00 & 0.00 & 0.00 & 0.00 & 0.00 & 0.00 & 0.00 \\
\hline & $\%$ Total & 0.00 & 0.00 & 0.00 & 0.00 & 0.00 & 0.00 & 0.00 & 0.00 \\
\hline \multirow{2}{*}{$3-4$} & $E(\mathrm{kWh} / \mathrm{m})$ & 0.00 & 0.00 & 0.00 & 78.77 & 69.80 & 9.47 & 0.00 & 158.04 \\
\hline & $\%$ Total & 0.00 & 0.00 & 0.00 & 0.53 & 0.48 & 0.03 & 0.00 & 1.04 \\
\hline \multirow{2}{*}{$2-3$} & $E(\mathrm{kWh} / \mathrm{m})$ & 0.00 & 0.00 & 34.22 & 207.95 & 26.33 & 0.00 & 0.00 & 268.49 \\
\hline & $\%$ Total & 0.00 & 0.00 & 0.69 & 2.77 & 0.24 & 0.00 & 0.00 & 3.70 \\
\hline \multirow{2}{*}{$1-2$} & $E(\mathrm{kWh} / \mathrm{m})$ & 0.00 & 0.33 & 215.08 & 126.26 & 59.38 & 0.00 & 0.00 & 401.04 \\
\hline & $\%$ Total & 0.00 & 0.04 & 13.16 & 4.18 & 1.29 & 0.00 & 0.00 & 18.66 \\
\hline \multirow{2}{*}{$0.5-1$} & $E(\mathrm{kWh} / \mathrm{m})$ & 0.00 & 46.29 & 125.58 & 7.75 & 0.45 & 0.00 & 0.00 & 180.06 \\
\hline & $\%$ Total & 0.00 & 15.51 & 25.97 & 0.87 & 0.09 & 0.00 & 0.00 & 42.45 \\
\hline \multirow{2}{*}{$<0.5$} & $E(\mathrm{kWh} / \mathrm{m})$ & 0.00 & 9.51 & 18.91 & 3.54 & 0.27 & 0.00 & 0.00 & 32.23 \\
\hline & $\%$ Total & 0.00 & 11.75 & 14.48 & 7.29 & 0.63 & 0.00 & 0.00 & 34.15 \\
\hline \multirow{2}{*}{ Total } & $E(\mathrm{kWh} / \mathrm{m})$ & 0.00 & 56.13 & 393.78 & 424.26 & 156.22 & 9.47 & 0.00 & 1039.86 \\
\hline & $\%$ Total & 0.00 & 27.30 & 54.30 & 15.64 & 2.73 & 0.03 & 0.00 & 100.00 \\
\hline
\end{tabular}


Table 5. Percentage of total time in an average year of sea states in different ranges of mean wave direction and $H_{s}$, site D.

\begin{tabular}{|c|c|c|c|c|c|c|c|}
\hline \multirow{2}{*}{ Direction } & \multicolumn{7}{|c|}{$H_{s}(m)$} \\
\hline & $<0.5$ & $0.5-1$ & $1-2$ & $2-3$ & $3-4$ & $>4$ & Total \\
\hline $\mathrm{N}$ & 0.00 & 0.02 & 0.00 & 0.00 & 0.00 & 0.00 & 0.02 \\
\hline NNE & 0.01 & 0.01 & 0.01 & 0.00 & 0.00 & 0.00 & 0.02 \\
\hline $\mathrm{NE}$ & 0.02 & 0.04 & 0.01 & 0.00 & 0.00 & 0.00 & 0.06 \\
\hline ENE & 0.04 & 0.07 & 0.01 & 0.00 & 0.00 & 0.00 & 0.13 \\
\hline $\mathrm{E}$ & 0.13 & 0.24 & 0.07 & 0.00 & 0.00 & 0.00 & 0.44 \\
\hline ESE & 0.41 & 0.60 & 0.14 & 0.01 & 0.00 & 0.00 & 1.16 \\
\hline SE & 1.32 & 3.17 & 2.04 & 0.49 & 0.14 & 0.00 & 7.16 \\
\hline SSE & 6.73 & 13.34 & 6.07 & 1.46 & 0.39 & 0.00 & 27.99 \\
\hline $\mathrm{S}$ & 9.98 & 10.04 & 3.51 & 0.41 & 0.02 & 0.00 & 23.97 \\
\hline SSW & 9.11 & 7.85 & 2.97 & 0.53 & 0.10 & 0.00 & 20.55 \\
\hline SW & 5.16 & 6.16 & 3.38 & 0.74 & 0.36 & 0.00 & 15.80 \\
\hline WSW & 0.95 & 0.80 & 0.44 & 0.06 & 0.03 & 0.00 & 2.28 \\
\hline $\mathrm{W}$ & 0.19 & 0.09 & 0.02 & 0.00 & 0.00 & 0.00 & 0.30 \\
\hline WNW & 0.05 & 0.02 & 0.00 & 0.00 & 0.00 & 0.00 & 0.07 \\
\hline NW & 0.01 & 0.00 & 0.00 & 0.00 & 0.00 & 0.00 & 0.02 \\
\hline NNW & 0.01 & 0.01 & 0.00 & 0.00 & 0.00 & 0.00 & 0.02 \\
\hline Total & 34.15 & 42.45 & 18.65 & 3.70 & 1.04 & 0.00 & 100.00 \\
\hline
\end{tabular}

